\title{
Escola não é lugar para o medo: o uso de fotografias de smartphones em sala de aula e na internet
}

\author{
The school is not a place for fear: the use of smartphones' \\ photography in the classroom and in the internet
}

Fábio d'Abadia de Sousa, Universidade Federal do Tocantins, Brasil (dabadia@mail.uft.edu.br)

Carolina Silva Sousa, Centro de Investigação em Educação e Psicologia, Portugal (csousa@ualg.pt)

Resumo: A nossa discussão, neste texto, gira em torno de algumas sugestões relacionadas ao resultado da presença de algumas das novas tecnologias da informação em sala de aula, principalmente quando se trata do uso de fotografias digitais feitas por estudantes a partir de smartphones. Partimos da hipótese de que uma parte da rede de ensino em todos os níveis, ainda não percebeu que pode, sim, auxiliar as crianças, adolescentes e jovens adultos a lidar com as novas tecnologias mesmo que, às vezes, alguns dos nossos estudantes pareçam saber manusear com mais desenvoltura do que nós, professores, alguns dos gadgets de acesso à internet. Defendemos que a participação dos professores é algo necessário e essencial, principalmente na orientação aos estudantes dos aspectos éticos do uso de fotografias na sala de aula e na internet.

Palavras-Chave: fotografia, sala de aula, tecnologias da informação

\begin{abstract}
The Our discussion in this paper is based in some suggestions related to some results of the use of new technologies of information in class-rooms, especially the use of digital photography made by students with smartphones. We start our suggestions based in the hypothesis that an important part of the teaching network, has not realized yet, that it is possible to help children, teenagers and young adults do deal with the new technologies of information, even though some of our students seem, sometimes, more skillful, than us, the teachers, in the use of some of the gadgets that allows to access internet. We defend that the participation of the teachers is something necessary and essential, especially in the orientation of the ethical aspects of the use of photography in the classroom.
\end{abstract}

Keywords: photography, class-rooms, technologies of information 
O medo seria, conforme a visão Bauman (2008), um dos elementos definidores da sociedade contemporânea ou pós-moderna, que ele chama de "líquidomoderna". Às vezes real, às vezes, imaginário, ele nos acompanha quase o tempo todo. Temos tantos medos, solitários ou coletivos, que, segundo este autor, sofremos da sindrome do Titanic:

Os temores emanados da "síndrome do Titanic" são os de um colapso ou catástrofe capaz de atingir todos nós, ferindo cega e indiscriminadamente, de modo aleatório e inexplicável, e encontrando todos despreparados e indefesos. Há, contudo, outros medos não menos, se é que não mais, aterrorizantes: o medo de ser pinçado sozinho da alegre multidão, ou no máximo separadamente, e condenado a sofrer solitariamente enquanto todos os outros prosseguem seus folguedos. O medo de uma catástrofe pessoal. $\mathrm{O}$ medo de se tornar um alvo selecionado, marcado para a ruína. $\mathrm{O}$ medo de cair de um veículo em rápida velocidade, ou de ser jogado pela janela, enquanto o resto dos viajantes, com os cintos de segurança devidamente afivelados, acha a viagem ainda mais divertida. O medo de ser deixado para trás. $\mathrm{O}$ medo da exclusão (Bauman, 2008, p.29). (Grifos do autor).

A pandemia da Covid-19, que atingiu milhões e milhões de pessoas em todo o mundo, de forma indiscriminada, em 2020, só confirma que temos motivos bem reais para sofrermos da "Síndrome de Titanic". Parece que a qualquer momento um meteoro gigante vai cruzar os céus e cair sobre nossas frágeis e atormentadas cabeças. Parece que a qualquer momento a floresta ao lado, ou mesmo do outro canto mundo, vai entrar em combustão, nada espontânea, e nos queimará vivos ou deixará o ar irrespirável e o planeta insuportavelmente quente.

O medo da exclusão é um dos mais ressaltados por Bauman, que cita os reality shows como exemplos de tentativa de exorcismo que a sociedade contemporânea pratica para tentar lidar com o pavor do ostracismo. Com a migração de parte da nossa vida social para a internet, parece que o medo da exclusão se intensificou mais ainda. Isso porque, no mundo digital, as exclusões são mais frequentes ainda que na vida real. Todos nós sabemos que a qualquer momento podemos ser excluídos dos mais diversos grupos aos quais nos filiamos nas redes sociais. Basta uma palavra errada ou uma foto considerada "feia" ou "inconveniente" para que sejamos "deletados". Ou como dizem agora "cancelados". A nossa aparência também pode atrair a ira dos "linchadores virtuais", que, de maneira implacável, podem voltar sua ira contra qualquer um que não esteja de acordo com seus inquisitórios padrões de beleza.

As possibilidades de sofrermos linchamentos virtuais e a exclusão de grupos da internet são apenas uma das faces sombrias dos relacionamentos líquidos da contemporaneidade. Além desses, o mundo virtual oferece muitos outros perigos reais e traumatizantes aos desavisados que navegam por seus labirintos. E é aí que acreditamos que nós, professores, podemos começar a fazer a diferença da vida dos nossos alunos, orientando-os, durante nossas aulas, sobre os lados perversos da internet.

Apesar de sermos uma sociedade mergulhada num oceano de imagens, ainda somos, de certa forma, quase analfabetos para a leitura das mensagens subliminares por trás de tanta informação imagética. As imagens gozam de uma credibilidade um tanto exagerada, o que favorece o uso manipulativo delas.

E tendemos a acreditar muito mais no que vemos do que no que ouvimos. Pense na diferença entre "testemunha ocular" e um "mero ouvir falar" (você alguma vez ouviu falar em "testemunha auricular" ou um "mero ver falar"? As imagens são muito mais "reais" do que palavras impressas ou faladas. As histórias que contam ocultam quem as conta, "aquele (ou aquela) que poderia mentir" e, portanto, desinformar. Diferentemente dos intermediários humanos, as câmeras "não mentem", "dizem a verdade" (ou pelo menos é o que fomos treinados a acreditar). Graças à imagem, cada um de nós pode, como desejavaa Edmund Husserl (que, mais que qualquer outro filósofo, era consumido pelo desejo de atingir a "verdade dos fatos"), retornar zurück zuden Sachen selbest - "de volta às coisas em si". Quando confrontados com uma imagem fotograficamenteleletronicamente obtida, nada parece erguer -se entre nós e a realidade; nada que possa capturar 
ou distrair o nosso olhar. "Ver para crer" significa "eu vou crer quando vir", mas também "no que eu vir, acreditarei" (Bauman, 2008, p. 29 e 30).

Este pensamento é muito provocante em relação a papel que a escola, em todos os níveis, poderia desempenhar, mas que, aparentemente, não desempenha. A fotografia existe (oficialmente) desde 1839. O cinema, que é uma adaptação de fotografia, nos acompanha desde os anos 20 do século XX, e a televisão nos acompanha deste os anos 50 do século passado. E até hoje, poucas escolas colocaram em seu currículo uma disciplina voltada para a proeficiência em "leitura de imagens". Por que não iniciarmos disciplinas com este propósito, neste momento, em que a imagem se absolutiza?

O novo geralmente assusta. Por exemplo, a própria televisão - a babá eletrônica - também foi muito mal recebido entre a comunidade acadêmica. Hoje, ao avaliarmos, por exemplo, o ensino telepresencial, podemos concluir que a televisão é uma das suas importantes aliadas. E com a pandemia do Coronavírus, e a adoção maciça do chamado "ensino remoto", a internet virou a "salvação" do ensino em todos os níveis. É claro que essa situação também ressaltou as lacunas entre os que possuem e os que não possuem acesso aos smartphones e toda a infraestrutura de interligação à rede mundial de computadores.

As discussões sobre sujeito e objeto, aparentemente fora de moda, são importantes para tentarmos entender melhor o papel que o professor pode assumir na era dos smartphones, principalmente nesta época em que a tecnologia e a inteligência artificial parecem querer começar a dominar o ser humano. "Todos nós sempre vivemos do esplendor do sujeito e da miséria do objeto. É o sujeito que faz história, é ele que totaliza o mundo" (Baudrillard, 1996, p. 1996). Mas a crença de um sujeito onipotente em relação ao objeto foi se deteriorando ao longo dos últimos anos e, hoje, uma importante corrente da psicologia e da psicanálise entende que o objeto é que domina o sujeito. Mas será que é esta a visão que deve prevalecer ao tratarmos do universo escolar contemporâneo e o seu estarrecimento diante da invasão tecnológica bem no meio das nossas salas de aula?
Será que o objeto, por exemplo, o smartphone e toda a força da internet e da tecnologia que ele incorpora, é capaz de desafiar e vencer o sujeito, neste caso o professor, o gestor escolar, o elaborador de currículo e, por conseqüência, o aluno? Este é um dos grandes dilemas de quem trabalha com o ensino na contemporaneidade. Na visão de Baudrillard, o sujeito pode apenas desejar, mas o objeto tem um trunfo aparentemente muito maior: ele pode seduzir:

Em nosso pensamento do desejo, o sujeito detém um privilégio absoluto, já que é ele que deseja. Mas tudo se inverte se passamos para um pensamento da sedução. Aqui não é mais o sujeito que deseja, é o objeto que seduz. Tudo parte do objeto e tudo a ele retorna, como tudo parte da sedução e não do desejo. $O$ privilégio imemorial do sujeito se inverte. Porque este é frágil, só podendo desejar, enquanto o objeto usa muito bem a ausência de desejo. Ele seduz por essa ausência de desejo, ele atua no outro pelo efeito do desejo, provocando-o ou anulando-o, exaltando-o ou desiludindo-o - quiseram ou preferiram esquecer essa potência (Baudrillard, 1996, p. 100).

Diante da irresistibilidade do objeto-tecnologia por parte do aluno, por exemplo, qual deve ser papel do sujeito-professor? A visão de Baudrillard, que na relação sujeito-objeto dá ganho de causa fácil ao objeto, parece fatalista demais. Será que é possível ir contra ela? Ou, será que é possível não ir contra ela? Diante de tamanho dilema e das conseqüências nefastas de o professor-sujeito sucumbir à tecnologiaobjeto, só resta uma alternativa ao professor: a resiliência. É preciso acreditar que somos capazes de alcançar a vitória não só para nós mesmos, mas principalmente pelo nosso aluno. Um professor derrotado corresponde a uma sala inteira de alunos derrotados. Então, não é possível cruzar os braços e aceitar, sem nenhuma luta, a vitória do aparentemente poderoso adversário.

Em primeiro lugar, nós, professores, não precisamos temer, de forma nenhuma, o uso das novas tecnologias em sala de aula. É preciso que deixemos de lado todo e qualquer medo em relação às novas tecnologias da informação e da Internet, e que ocupe- 
mos o nosso lugar nesta nova era que, quer queiramos ou não, já está nós engolindo de maneira inexorável. A pandemia de Covid-19 apenas acelerou este processo. Não é possível mais retornar. Estamos numa situação que vai além de seguir o mais maquiavélico dos preceitos: de juntar-se ao inimigo se não puder vencê1o. Trata-se de ocupar um lugar que já está, por direito, reservado única e exclusivamente a nós, professores. E enquanto não o ocuparmos, ele continuará vazio. E nossos alunos continuarão desamparados e aprendendo a lidar com o mundo da virtualidade quase sem nenhuma orientação.

O sistema educacional quase sempre demonstrou-se ser conservador diante das novidades do mundo exterior. Com a pandemia do Coronavírus, temos sido obrigados a deixar o nosso conservadorismo de lado. Em muitos lugares do mundo, o "ensino remoto" tornou-se a única forma de acesso aos nossos alunos. É claro que é algo frio chegarmos aos nossos estudantes apenas pela tela do notebook ou do smartphone! Mas a única a escolha que temos é não chegarmos a eles de forma nenhuma. Talvez um dos grandes legados da pandemia seja a confirmação de que um aperto de mão ou um abraço, gestos simples e corriqueiros que muitos de nós não dávamos o devido valor, são contatos fundamentais nas nossas relações. Neste momento de "ensino remoto", o nosso abraço e o nosso aperto de mão somente são possíveis, infelizmente, por meio da tecnologia. Então, façamos dela uma aliada e não uma inimiga.

Gómez e López (2014, p.16) apontam que os meios de comunicação podem ser muito úteis na construção da cidadania das pessoas em fase de aprendizado escolar, mas ressaltam que esses meios podem oferecer várias situações de risco, principalmente para as crianças, por isso, defendem que seja trabalhado o espírito crítico relação a todos os meios acessíveis a crianças e jovens. "Esto requiere del trabajo colaborativo de toda la ciudadania para conseguir desarrollar en las personas la capacidad de consumir los médios de comunicación de un modo autônomo e inteligente" (Isso requer um trabalho conjunto de toda a cidadania para conseguir desenvolver nas pessoas a capacidade de consumir os meios de comunicação de um modo autônomo e inteligente). (Tradução nossa).
Na opinião de Gómez e López (2014) é surpreendente notar como os mais jovens utilizam com a agilidade todos os recursos tecnológicos que têm ao seu redor, chegando a superar, sem dúvidas, as competências de pessoas adultas. Esta constatação desses autores se a aplica, com precisão, também ao espaço escolar. Se um aluno demonstrar maior conhecimento que nós em relação ao uso e ao acesso de aplicativos, por exemplo, nós temos várias saídas honrosas. A primeira é reconhecer o conhecimento do aluno e conclamá-lo a nos ajudar. Humildade nunca fez mal a ninguém, principalmente a quem ensina. Uma segunda alternativa é exigir dos gestores e mantenedores escolares cursos que nos capacitem a lidar melhor com o uso das novas tecnologias. Nós, professores, não podemos ser responsabilizados por uma omissão que não é nossa, mas de toda a cadeia de gestores escolares, que vai deste o Ministério da Educação e o reitor da universidade até o coordenador pedagógico da creche.

Castells (2005), um dos principais pensadores da sociedade em rede, critica severamente os intelectuais tradicionais, porque, segundo ele, parecem não estar a fazer esforços para se adequarem à nova realidade trazida pelas novas tecnologias. Castells não cita especificamente os pensadores da área de educação, mas a carapuça cabe em todos nós. Castells afirma que os intelectuais da contemporaneidade estão:

....cada vez mais incapazes de compreender o mundo em que vivem, e aqueles que estão minados no seu papel público, são particularmente críticos à chegada de um novo ambiente tecnológico, sem na verdade conhecerem muito sobre os processos acerca dos quais elaboram discursos. No seu ponto de vista, as novas tecnologias destroem empregos, a Internet isola, nós sofremos de excesso de informação, a info-exclusão aumenta a exclusão social, o Big Brother aumenta a sua vigilância grãs a tecnologias digitais mais potentes, o desenvolvimento tecnológico é controlado pelos militares, o tempo das nossas vidas é persistentemente acelerado pela tecnologia, a biotecnologia leva à clonagem humana e aos maiores desastres ambientais, os países do Terceiro Mundo não precisam de tecnologia mas da satisfação das suas 
necessidades humanas, as crianças são cada vez mais ignorantes porque estão sempre a conversar e a trocar mensagens em vez de lerem livros, ninguém sabe quem é quem na Internet, a eficiência no trabalho é sustentada em tecnologia que não depende da experiência humana, o crime e a violência, e até o terrorismo, usam a Internet como um medium privilegiado, e nós estamos rapidamente a perder a magia do toque humano. Estamos alienados pela tecnologia. Ou então, nós podemos reverter tudo o que eu acabei de escrever exactamente para o seu sentido oposto, e entraremos no paraíso da realização e da criatividade plena do ser humano, induzidas pelas maravilhas da tecnologia, na versão em espelho das mesmas mitologias, desta vez propagada por consultores e futurologistas, muitas vezes em representação de um dado papel para empresas de tecnologia (Castells, 2005, p. 19-20).

Acreditamos que a sala de aula é um lugar privilegiado para a transmissão de conhecimentos. E isso se aplica tanto para ensinamentos sobre passado quanto para aqueles relacionados ao presente e ao futuro. Quando fixamos os nossos conteúdos apenas em assuntos relacionadas ao que já aconteceu - e ignoramos a realidade contemporânea e a que se avizinha - estamos, de certa forma, dizendo que apenas o que já passou é importante. A prevalência do conhecimento apenas sobre o passado faz com que o aluno não se veja representado nas matérias ministradas, o que, possivelmente, contribui para geração de desinteresse e falta de identificação com a escola de uma forma geral.

Tem se tornado comum, por exemplo, muitas escolas - principalmente as particulares - se vangloriarem com o fato de oferecerem tablets para que os alunos os utilizem em sala de aula em matérias específicas. Será que apenas oferecer tablets em determinadas disciplinas é o suficiente para trazer o ensino para o século XXI? O tablet é apenas um suporte para o conhecimento, tal como um livro, só que mais sofisticado, é claro!

Ficar a arrastar o dedo na tela de um gadget não é o suficiente para trazer o ensino para a contemporaneidade, se o conteúdo for apenas passadista. Como um tablet é também uma câmera fotográfica, por que não levar os alunos a um parque e solicitar que eles fotografem exemplos de fauna e flora presentes naquele espaço, para, depois, em sala de aula, reunir todas as fotos, fazer um debate sobre a experiência e em seguida montar uma exposição do mural da escola? Por que não solicitar, nas aulas de redação, que o aluno faça um perfil de um de seus colegas de sala de aula e $o$ apresente junto com uma foto deste colega.

Fernandes (2011), numa atividade que considero excelente e que pode servir de exemplo para outros professores, utilizou a fotografia para uma experiência de discussão sobre identidade com crianças do $5^{\circ}$ ano de uma escola de ensino fundamental, em Briteiros, no norte de Portugal. O objetivo foi avaliar a eficácia de novas estratégias de ensino/aprendizagem na disciplina Educação Visual e Tecnológica capazes de fomentar a compreensão do conceito de identidade:

A reflexão sobre o conceito de identidade, em grupo/turma, contribuiu para uma melhor compreensão de si e do outro. A identidade pôde ser entendida como um conjunto de características próprias e exclusivas de cada aluno que, ao serem experimentadas e apresentadas diante de todos, não só potenciaram 0 conhecimento de si, como também o conhecimento acerca dos demais (Fernandes, 2011, p. 114).

Em sua pesquisa, que resultou numa dissertação de mestrado, Fernandes (2011, p. 115) chama a atenção para o papel do professor como elemento fundamental na reciclagem do sistema educativo, pois ele "age, reflete, modifica estratégias, altera os planos, luta pela mudança" e que resulta num sistema educacional que desenvolve "soluções para as necessidades e desafios sociais contemporâneos".

Os nossos alunos mais jovens já nasceram nesta era em que ocorre o uso maciço do telefone celular para as mais diferentes possibilidades de comunicação. Manusear os seus aparelhos com destreza eles já sabem. Então, o diferencial da escola hoje é instruí-los para uma etiqueta em relação ao uso comedido e ético do seu aparelho de comunicação.

Nos anos 70 do século passado, bem antes da digitalização fotográfica e da popularização da internet, Freund (1995, p. 19) já nos chamava a atenção para a importância que a fotografia adquiria na sociedade: 
"Na vida contemporânea a fotografia desempenha um papel capital. Quase não existe uma atividade humana que não a empregue, de uma maneira ou de outra. Tornou-se indispensável para a ciência e para a indústria“. Esta autora ressaltava que a fotografia tinha tornado-se tão presente na vida social que, de tanto convivermos com a ela já nem a notávamos. $\mathrm{E}$ a enorme importância que a fotografia assumiu na nossa sociedade talvez esteja principalmente neste fato de não considerarmos o poder que se esconde por trás de imagens aparentemente ingênuas e inocentes.

De agora em diante a fotografia faz parte da vida quotidiana. Incorporou-se de tal modo na vida social que, à força de vê-la, não mais a vemos. Um dos seus traços mais característicos é ser igualmente recebida em todos os estratos sociais. Tanto se a encontra no alojamento do operário e do artesão como em casa do comerciante, do funcionário e do industrial. É nisso que reside a sua grande importância política. Ela é o meio de expressão típico de uma sociedade determinada, assente numa civilização tecnológica e fundada na hierarquia das profissões. Ao mesmo tempo ela tornou-se para essa sociedade num instrumento de primeira ordem. $\mathrm{O}$ seu poder de reproduzir exatamente a realidade exterior - poder inerente à sua técnica - empresta-lhe um caráter documental e fá-la aparecer como o processo de reprodução mais fiel, o mais imparcial, da vida social (Freund, 1995, p. 20).

Outra característica que reforça o poder da fotografia é a falsa impressão que ela passa de ser um instrumento que retrata a realidade de maneira fiel e objetiva. Neste sentido, Gisele ressalta, no entanto, que a objetividade da fotografia é apenas fictícia:

A objetiva, esse olho pretensamente imparcial, permite todas as deformações possíveis da realidade, já que o caráter da imagem é determinado, a cada vez, pelo modo de ser do operador e pelas exigências dos seus mandantes. A importância da fotografia não reside, portanto, apenas no fato de ela ser uma criação, mas sobretudo no fato de ela ser um dos meios mais eficazes de conformar as nossas ideias e de influenciar o nosso comportamento (Freund, 1995, p. 20).
Ao observarmos o uso, talvez excessivo (às vezes) de imagens nas redes sociais, percebemos o quanto a fotografia se tornou um dos principais instrumentos de expressão das pessoas na sociedade contemporânea. Ela virou uma forma de participação e intervenção em numa sociedade que a cada dia parece que nos isola mais. Neste sentido, ainda é fortemente atual o pensamento de Freund de que a fotografia fornece aos cidadãos a sensação pertencimento:

A imagem responde à necessidade cada vez mais urgente, por parte do homem, de dar uma expressão à sua individualidade. Hoje, e apesar dos aperfeiçoamentos incessantemente crescentes da vida material, o homem sente-se cada vez menos implicado no jogo de acontecimentos, relegado para um papel cada vez mais passivo. Fazer fotos parecethe uma exteriorização dos seus sentimentos, uma espécie de criação. Daí o numero crescente de fotógrafos amadores, que se situa hoje nas centenas de milhões e que tende a crescer cada vez mais. (Freund, 1995, p. 20).

O que talvez Freund não imaginasse é que no século XXI o número de fotógrafos amadores atingisse a casa dos bilhões, ou seja, cada um de nós tornou-se um fotógrafo amador, agora não mais com a câmera fotográfica, mas com o smartphone conectado à internet. A adesão de bilhões à fotografia possivelmente ocorre porque a fotografia é uma das mais eficientes maneiras de nos mostrarmos para este mundo, cada vez mais tecnológico e virtualizado desde o surgimento das redes sociais. Hoje, até mesmo a namorada ou o namorado já está sendo escolhido via redes sociais. E as estatísticas apontam que as pessoas que mais recebem propostas de pretendentes são aquelas que postam as melhores fotos. $\mathrm{O}$ caráter e a compatibilidade com a pessoa da foto é analisado posteriormente. $\mathrm{O}$ mesmo ocorre em situações de relacionamentos "relâmpagos", como no caso do aplicativo Tinder, por exemplo, em que a foto da pessoa tornou-se mais importante que a própria pessoa.

Talvez um dos maiores paradoxos da contemporaneidade seja o fato que, mesmo que com um excesso de possibilidades de comunicação, parece que nunca estivemos tão sós e isolados. É por isso que o papel 
do professor torna-se a cada dia mais essencial, para, entre outras coisas, alertar o aluno sobre os exageros da vida virtual e, é claro, para mostrar as vantagens de contatos e relacionamentos reais. $\mathrm{O}$ que não se pode fazer é continuar a ignorar esta vida na qual quase todos os nossos alunos estão mergulhados.

Quando Bauman (2009) nos chama a atenção para o fato de que vivemos, na pós-modernidade, uma época de medo, ele explica que isso acontece porque os valores e instituições que serviram de referência se liquefazem. A sensação de insegurança afeta a todos nós e é generalizada, conforme observa o autor:

O que mais amedronta é a ubiquidade dos medos; eles podem vazar de qualquer canto ou fresta de nossos lares e de nosso planeta. Das ruas escuras ou das telas luminosas dos televisores. De nossos quartos e de nossas cozinhas. De nossos locais de trabalho e do metrô que tomamos para ir e voltar. De pessoas que encontramos e de pessoas que não conseguimos perceber. De algo que ingerimos e de algo com o qual nossos corpos entraram em contato (Bauman, 2009, p. 11)

E o pavor de sermos contaminados a qualquer momento, como ocorre agora com a pandemia de Coronavírus, apenas nos empurra mais e mais para o refúgio da tecnologia. E diante do desmoronamento de costumes que nos sustentaram até o momento, talvez um dos principais fatores de assombramento da sociedade da era do smartphones seja o medo da solidão. Este é um problema tão grave que governos, como o da Inglaterra, por exemplo, começam a criar ministérios especificamente para buscar algumas alternativas que amenizem o isolamento social de parte significante de sua população, principalmente as gerações mais envelhecidas, já que, aparentemente, os jovens, por meio das redes sociais, têm conseguido lidar melhor com este fantasma da contemporaneidade. E quanto mais a tecnologia avança, mais solitários parece nos tornamos. Até mesmo o simples ato de falar ao telefone com os amigos e familiares começa a ficar obsoleto.

Nós chegamos ao ponto de termos que provar, com certa frequência, que não somos simples robôs. Isso mesmo! Chegamos a esse tempo absurdo em que a tecnologia nos humilha, nos torna invisíveis e nos deixa cada vez mais ultrajados, temerosos e solitários. É o que acontece atualmente quando acessamos alguns serviços públicos e particulares por meio digital. "Prove que você é você mesmo! Prove que você não é um robô!" Os meios de comunicação têm informado, nos últimos meses, casos intrigantes de pessoas aposentadas, no Japão, que cometem pequenos crimes apenas para serem presas. Alguns alegam que é porque o valor que recebem como aposentados é muito baixo, mas outros dizem que o verdadeiro motivo é uma tentativa de fugir da solidão. "Em última análise, o relacionamento entre as pessoas mudou. As pessoas se isolaram mais. Eles não se encaixam nesta sociedade. Não conseguem aguentar a solidão", diz Kanichi Yamada, de 85 anos, que era criança quando foi retirado dos escombros após o lançamento da bomba atômica em Hiroshima (BBC Brasil, 2019).

É claro que a tecnologia tem esse lado perverso! Mas tem outras facetas menos assustadoras também! Desde o início da pandemia de Covid-19, por exemplo, os transtornos e doenças mentais cresceram consideravelmente por causa da imposição do isolamento social. Mas a tecnologia também possibilitou a cura, ao permitir 0 acesso a profissionais especializados no tratamento de transtornos mentais via internet. Não podemos ignorar, sobretudo, o alerta de Freund (1995, p. 20), de que a fotografia, "pretensamente imparcial, permite todas as deformações possíveis da realidade". Se fecharmos os olhos e nos limitarmos apenas a exigir que os celulares sejam desligados em sala de aula, estaremos sendo omissos e distantes da vida "virtual" que hoje faz parte não só da vida dos nossos alunos, mas de toda a sociedade.

A escola não pode ignorar a grande importância que a fotografia adquiriu a partir do surgimento das redes sociais, o novo espaço de encontro de pessoas quer para negócios quer para assuntos da vida privada. $\mathrm{O}$ que já era gigantesco se intensificou consideravelmente com a pandemia de Coronavírus. $\mathrm{O}$ isolamento social imposto a milhões e milhões de pessoas nos mais diversos países fez, em determinado momento, que as redes fossem a única forma de contato com o mundo externo. 
O uso maciço de fotografias nas redes sociais talvez tenha até aproximado mais as pessoas, mas ele também criou um terreno fértil para a multiplicação dos "haters", palavra da língua inglesa que literalmente significa "odiadores" e que se refere àquelas pessoas que dedicam a ofender e a espalhar todo o tipo de preconceito pelas redes. Geralmente são indivíduos oriundos de grupos privilegiados da sociedade e que, por trás de seus rancores, na verdade, travam uma luta sangrenta contra aqueles que podem ascender socialmente e ameaçarem seus privilégios seculares. Covardemente, agridem principalmente pessoas pertencentes às minorias sociais mais vulneráveis.

Infelizmente, as redes sociais reproduzem os mesmos preconceitos da sociedade já cristalizados na grande mídia, por exemplo. Pessoas das chamadas minorias sociais são agredidas, aparentemente, apenas por não se encaixarem nos padrões estéticos estabelecidos pelos donos do poder. Ou apenas por serem mulheres, por exemplo. É por isso que é tão importante a participação da escola, em todos os níveis, na tentativa de estabelecer um mínimo de ética, proteção e, principalmente, conscientização aos estudantes atacados para que eles saibam por que estão sendo violentamente desrespeitados. A questão não é só estética, mas sobretudo política. Apregoar os valores de solidariedade e respeito às diferenças individuais é algo urgente na construção de uma internet mais fraterna. Os assédios e importunamentos aos colegas mais indefesos migraram dos corredores e pátios das escolas para as redes sociais. Crianças, adolescentes e jovens adultos são xingados e hostilizados em virtude da cor da pele, estilo de cabelo, forma de se vestirem, origem social, gênero, valores religiosos e orientação sexual. Os "valentões" da internet praticam o chamado ciber-bullying quase sem nenhum constrangimento. Até quando a escola vai ficar omissa diante deste fenômeno?

Conforme explica Sakamoto (2016), grupos privilegiados da sociedade, sob o manto de que estão apenas a exercer o seu direito à liberdade de expressão, divulgam, sem nenhum constrangimento, ofensas a pessoas das minorias sociais. Para este autor, trata-se de uma disputa simbólica na qual a linguagem eufemística, que atenua e mascara o peso das ofensas, é a prin- cipal arma. O combate à crueldade suavizada deve vir, conforme apregoa o jornalista, em uma linguagem nada eufemística:

Da mesma forma que a pessoa que defende que brancos tenham mais direitos que negros e indígenas, que homens devem mandar e mulheres, obedecer, que ricos precisam ser mais protegidos do que pobres, que ciclistas são comunistas e devem ser combatidos, que a mulher que aborta deve ir presa e que casamento homoafetivo deveria ser proibido está "exercendo simplesmente seu direito à liberdade de expressão".

Por isso é tão importante os grupos que não detêm poder econômico, político e midiático participarem ativamente dessa disputa simbólica e usarem os termos que estão à altura da agressão que sofrem: isso é machismo, racismo, homofobia, xenofobia, preconceito.

Violência, na verdade, é manter o silêncio diante de uma injustiça, o que inclui você e eu.

(Sakamoto, 2016, p. 48). (Grifos do autor.)

Ao refletirmos sobre este pensamento de Sakamoto e adaptá-lo ao uso de fotografias nas redes sociais, concluímos que a fuga de muitas pessoas da internet por causa dos "haters" não e a melhor saída. Xingálos de volta também não. A afronta é mostrar-se na rede com orgulho da aparência que tem, mesmo que ela não corresponda ao padrão ditatorial que os linchadores virtuais querem impor. A fotografia é, sim, um instrumento de construção de identidades. A ridicularização da foto de uma pessoa apenas em virtude de sua aparência tem criado traumas e expulsado indivíduos das chamadas minorias sociais da internet. Essas pessoas, quando freqüentam as redes sociais, colocam tarjas em seus rostos, para não serem identificadas e se tornarem presas fáceis para os "haters". Será que vamos deixar os "valentões", mais uma vez, vencerem esta batalha e tornarem "invisíveis" aqueles que já são "invisibilizados" pela grande mídia? O cinema, a televisão e a publicidade já os excluíram uma vez. Com uma orientação correta, as redes sociais podem fazer de maneira diferente.

A internet é um avanço extraordinário na comunicação humana. E ela pertence a toda à humanidade $\mathrm{e}$ 
não só aos valentões e aos donos do poder que mandam no mundo desde os primórdios da civilização. Vamos, professores, tirar as tarjas dos rostos dos nossos alunos e ajudá-los a se mostrarem lindos e maravilhosos como realmente são! Feios são os que os oprimem e que os querem "invisíveis", é claro, para assim continuarem a manter seus históricos privilégios! Chega de medo e opressão em nossas escolas e na internet também! Vamos começar agora uma mudança que fará a internet do futuro mais inclusiva, democrática, solidária e realmente representativa de toda a variedade e beleza humanas.

\section{Referências}

Baudrillard, J. (1996). As estratégias fatais. Trad. Ana Maria Scherer. Rio de Janeiro: Rocco.

Bauman, Z. (2008). Medo líquido. Trad. Carlos Alberto Medeiros. Rio de Janeiro: Jorge Zahar.

BBC Brasil (2019). Aposentados na cadeia: os idosos japoneses que se esforçam para serem presos. BBC News Brasil. Retrieved from https://www.bbc.com/portuguese/geral-47086935

Castells, M. (2005). A Sociedade em Rede: do Conhecimento à Política. In M. Castells; G. Cardoso (Orgs.). A Sociedade em Rede - Do Conhecimento à Aç̧ão Política (pp. 17-30). Imprensa Nacional - Casa da Moeda.

Fernandes, S.D.M. (2011). Descobrir a identidade usando a fotografia: Investigação-acção numa turma do $5^{\circ}$ ano (Dissertação de mestrado). Instituto Politécnico de Viana do Castelo: Portugal. Retrieved from http:// hdl.handle.net/20.500.11960/1536

Freund, G. (1995). Fotografia e sociedade. Trad. Pedro Miguel Frade. Lisboa: Vega.

Gómez, I.A.G., \& López, P.M. (2014). Infancia y medios de comunicación: de los riegos a la apropiación creativa. In A.S.J. Hernandez, \& R. Kohli (dir.). Infancia en contextos de riesgos: XXV Años de la Convención sobre lós Derechos Del Niño (pp. 203-209). Granada: Editorial GEU.

Sakamoto, L. (2016). O que aprendi sendo xingado na internet. São Paulo: LeYa. 